\title{
Sodium Dodecyl Sulfate Modified-Zeolite as a Promising Adsorbent for the Removal of Natural Organic Matter From Aqueous Environments
}

\author{
Amir Hosein Mahvi, ${ }^{1,2}$ Mehdi Vosoughi, ${ }^{3,4, *}$ Mohammad Javad Mohammadi, ${ }^{3,5}$ Anvar Asadi, ${ }^{6}$ \\ Bayram Hashemzadeh, ${ }^{7}$ Amir Zahedi, and Soudabeh Pourfadakar ${ }^{3}$ \\ ${ }^{1}$ Department of Environmental Health Engineering, School of Public Health, Tehran University of Medical Sciences, Tehran, IR Iran \\ ${ }_{2}^{2}$ Center for Solid Waste Research, Institute for Environmental Research, Tehran University of Medical Sciences, Tehran, IR Iran \\ 3 Department of Environmental Health Engineering, School of Public Health, Ahvaz Jundishapur University of Medical Sciences, Ahvaz, IR Iran \\ ${ }_{5}^{4}$ Student Research Committee, Ahvaz Jundishapur University of Medical Sciences, Ahvaz, IR Iran \\ ${ }_{5}$ Clinical Research Development Center, Razi Teaching Hospital, Ahvaz Jundishapur University of Medical Sciences, Ahvaz, IR Iran \\ ${ }_{6}$ Clinical Research Development Center, Razi Teaching Hospital, Ahvaz Jundishapur University of Medical Sciences, Ahvaz, IR Iran
6 Department of Environmental Health, School of Public Health, Shahid Beheshti University of Medical Sciences, Tehran, IR Iran \\ 7 Department of Environmental Health, School of Public Health, Shahid Beheshti University of Medical Sciences, Tehran, IR Iran
${ }_{\text {Department of Environmental Health, Khoy School of Nursing and Public Health, Urmia University of Medical Sciences, Urmia, IR Iran }}$ \\ ${ }^{*}$ Corresponding author: Mehdi Vosoughi, Department of Environmental Health Engineering, School of Public Health, Ahvaz Jundishapur University of Medical Sciences, Ahvaz, IR \\ Iran. Tel: +98-9386939465, Fax:+98-6113361544, E-mail: mvn_20@yahoo.com
}

Received 2015 May 14; Revised 2015 August 31; Accepted 2015 September 5.

\begin{abstract}
Background: High concentrations of natural organic matter (NOM) may cause the production of harmful compounds in treated drinking water. Surfactant-modified zeolites (SMZs) with various loadings of sodium dodecyl sulfate(SDS) have been used as adsorbents to remove NOM from aqueous solution. SMZ has presented higher NOM adsorption more efficiency than natural zeolite. NOM affects the quality of drinking water in several points.

Objectives: The purpose this study was to investigate the SDS-modified isotherm of natural Iranian zeolite obtained from Semnan mines, for the removal of NOM from aqueous solution.

Materials and Methods: The adsorption of NOM onto SDS-modified zeolite as a function of contact time, initial NOM concentrations, adsorbent dose and solution $\mathrm{pH}$ was investigated. The isotherm experiments were carried out with fixing the adsorbent dose and varying the initial concentration of NOM.

Results: The results indicated that SDS-modified zeolite showed greatly enhanced adsorption capacity. Findings revealed that the Langmuir isotherm best described the NOM adsorption on the adsorbent. The adsorption isotherm was well fitted to the Langmuir model. The maximum adsorption capacity of SMZ with surfactant bilayer coverage for $\mathrm{NOM}$ was $111 \mathrm{mg} / \mathrm{g}$ at $25^{\circ} \mathrm{C}$ and $\mathrm{pH}=5$.

Conclusions: The findings of this study showed that the modification of natural zeolites can achieve higher adsorption capacity for organics. In addition, based on the results, natural zeolite being modified with SDS as a cationic surfactant had good efficiency for the adsorption of NOM.
\end{abstract}

Keywords: Natural Organic Matter, Modified Zeolites, Sodium Dodecyl Sulfate, Adsorption

\section{Background}

Humic compounds are considered as the biggest portion of natural organic matter (NOM), found in many surface water sources (1-3). NOM is one of the main components of organic matter, which is form the major portion of dissolved organic materials. NOM components are anionic molecules with surface functional carboxylic and phenolic groups (2, 4-6). High concentrations of NOM may produce harmful compounds in treated drinking water. The presence of NOM in raw water sources is unfavorable and has long been a problem for water supply system industries. Particularly, NOM affects the quality of drinking water in several points. Color is an important esthetic drinking water quality (7-9). In addition, NOM can bind synthetic organic pollutants (such as pesticides) and heavy metals and results in their transportation through the treatment units and distribution network (5,10-12). Furthermore, as a matter of the presence of high concentrations of NOM in raw water, chlorination of raw water can result in the production of disinfection byproducts (DBPS) such as trihalomethanes (THMS) during the chlorination process $(1,5,10)$. Therefore, the removal of NOM from drinking water resources is so important. There are various methods for the removal of NOM from raw water such as membrane processes (nanofilters and reverse osmosis), chemical coagulation and precipitation, advanced oxidation, and adsorption (11-15). Among the above processes, adsorption is the most applicable and acceptable method. Many different adsorbents including activated carbon, resin, unburned carbon, chitosan, and surfactant-modified bentonite have been ap-

Copyright ( 2016 , Health Promotion Research Center. This is an open-access article distributed under the terms of the Creative Commons Attribution-NonCommercial 4.0 International License (http://creativecommons.org/licenses/by-nc/4.0/) which permits copy and redistribute the material just in noncommercial usages, provided the original work is properly cited. 
plied for synthetic humic acid (HA) removal (10, 16-18). Marc Edwards' study showed that strongly acidic groups are predicted to be the key to the formation of strong surface complexes between organic molecules and oxide surfaces (19). Qunhui Zhou et al. studied the adsorption equilibrium and kinetics of an aquatic fulvic acid (XAD-8 resin extract) onto goethite ( $\alpha-\mathrm{FeOOH})(20)$. Chunli Ding examined the mechanisms controlling the adsorption of NOM on surfactant-modified iron oxide-coated sand (21). In recent years, natural zeolites have been studied for the removal of various pollutants from water and wastewater. Natural zeolites are hydrated aluminosilicate with structures of tetrahedrons $\mathrm{SiO}_{4}$ and $\mathrm{AlO}_{4}$ including water molecules, alkali and alkaline earth metals in their structures $(1,22)$. In this regard, natural zeolites can generally exchange cations with anions, making them appropriate for surface modification by cationic surfactant (3, 10). Cationic surfactant comprising positive groups can readily exchange its groups with the exchangeable cations on the external surface of zeolite, which results in improving the adsorption capacity $(1,23)$. To our knowledge, no studies have been performed in relation to NOM sorption on modified zeolite by sodium dodecyl sulfate (SDS). Furthermore, zeolites from different sources have different characteristics, which can affect their adsorption potentials.

\section{Objectives}

This study aimed to assess the efficiency of the SDS-modified isotherm of natural Iranian zeolite obtained from Semnan mines, for the removal of NOM from aqueous solutions for the first time.

\section{Materials and Methods}

\subsection{Materials}

Natural zeolite was purchased from Afrazand Co. Ltd The surface morphology of the zeolite was analyzed using scanning electron microscopy (SEM) (XL30 Philips, Holland). X-ray fractionation (XRF) (PW 2404 Philips, Holland) and X-ray diffraction (XRD) (Philips-XPERT) techniques were used to analyze the chemical composition of the zeolite samples, respectively. The NOM sodium salt was obtained from Sigma-Aldrich company. SDS was purchased from Merck company (Germany). The NOM solution samples were real and collected from Tehran Latiyan dam. Other chemicals used in this study were obtained from Merck.

\subsection{Preparation of Adsorbent}

The zeolite tuff was ground and sieved by $0.21-0.3 \mathrm{~mm}$ American Standard Test Sieve Series (ASTM). The milled zeolitic tuff was washed for several times to remove inorganic impurities; then, for dissolution of salts, the zeolite tuff was completely soaked in deionized water for 24 hours. To eliminate organic materials in the zeolite, it was then dried at temperature above $100^{\circ} \mathrm{C}$ in an oven for 24 hours $(24,25)$.

\subsection{Cationic Form of Zeolite}

Before the modification of the zeolite surface with the surfactant, to make monotonous adsorption sites on the zeolite surface with sodium, $10 \mathrm{~g}$ of zeolite was added to each conical flask containing $100 \mathrm{~mL}$ sodium chloride solution of $2 \mathrm{M}$ concentration. Then, the conical flasks were shaken by an incubator shaker $\left(150 \mathrm{rpm} ; 20^{\circ} \mathrm{C}\right)$ for 24 hours $(24,26)$. To prevent the possible intervention of chloride anions in the modification of zeolite, samples were washed several times with distilled water to remove the remaining chloride. The residual chloride in the supernatant of the premodified samples was determined by $\mathrm{AgNO}_{3}$ using the argentometry method (27). Finally, the samples were dried in oven at $50^{\circ} \mathrm{C}$ for 24 hours (22).

\subsection{Surfactant Modification of Zeolite}

Zeolite surfactant modification can improve the adsorption capacity. A monolayer will be formed when the surfactant concentration is equal to or less than its critical micelle concentration (CMC). The surfactant molecules will form a bilayer of surfactant on the surface of zeolite if the surfactant concentration in a solution exceeds the CMC (28). The surfactant modification of zeolite makes a hydrophobic environmental conditions for the partitioning of the organic molecules with low polarity and high molecular weight (29). The CMC of SDS is $1.8 \mathrm{mmol} / \mathrm{L}(24$, 26). To determine the effect of surfactant concentration on the adsorption of NOM, three initial concentrations of SDS surfactant $(0.5,1.8$ and $20 \mathrm{mmol} / \mathrm{L})$ were selected which were in lesser, equal, and higher concentrations than the CMC of the surfactant for modification. For the preparation of modified zeolite, $10 \mathrm{~g}$ of prepared cationic zeolite was put into a $200 \mathrm{~mL}$ conical flask containing $100 \mathrm{~mL}$ of different concentration of SDS (0.5, 1.8 and 20 $\mathrm{mmol} / \mathrm{L})$. Then, the flasks were shaken in an incubator shaker $\left(20^{\circ} \mathrm{C}, 150 \mathrm{rpm}\right)$ for 24 hours. The solid was washed with distilled water repeatedly until no $\mathrm{Br}$ - was detected by $\mathrm{AgNO}_{3}$ solution; then, it was dried in an oven at $50^{\circ} \mathrm{C}$ for 24 hours $(24,26)$. The zeolite modified with $0.5,1.8$ and $20 \mathrm{mmol} / \mathrm{L}$ of SDS solutions were named as surfactantmodified zeolites (SMZ) 1, SMZ2 and SMZ3, respectively.

\subsection{Adsorption Experiments}

To compare the efficiencies of NOM removal with different types of modified adsorbents, $100 \mathrm{~mL}$ of constant concentrations of NOM was poured into conical flasks, and then a fixed dose $(0.08 \mathrm{~g} / \mathrm{L})$ of different adsorbents was added to each flask. The solutions were shaken at the equilibrium time. The removal percentage of NOM was calculated using equation 1 . The adsorbent with higher 
adsorption toward NOM was chosen for using in the next experiments. All the adsorption experiments were carried out in a batch system. A stock solution of $1000 \mathrm{mg} / \mathrm{L}$ of NOM was prepared by dissolving special amounts of NOM in distilled water. This solution was diluted to obtain the required solutions. The kinetics of the adsorption were determined by analyzing the adsorption of NOM at different intervals. Total organic carbon (TOC) analyzer (TOC-VCSH, Shimadzu, Japan) was used to analyze NOM in the aqueous solutions. The effects of different doses of the adsorbent, which were ranging from 0.2 to $1.2 \mathrm{~g} / \mathrm{L}$, were examined. The influence of initial $\mathrm{pH}$ was studied in various ranges $(2-9)$ in a constant adsorbent dose. NOM adsorption experiments were performed to acquire isotherms at a fixed dose of the adsorbent for the time greater than equilibrium at $25^{\circ} \mathrm{C}$ in an incubator shaker (Innova 4340, USA); $0.1 \mathrm{~N} \mathrm{HCl}$ and $\mathrm{NaOH}$ prepared from the analytic grade chemicals were used for $\mathrm{pH}$ adjustment. The removal percentage of NOM was calculated using the following equation:

$$
\% \text { Removal of } \mathrm{NOM}=\left[\frac{C_{0}-C_{t}}{C_{0}}\right] \times 100
$$

Where $\mathrm{C}_{0}$ and $\mathrm{C}_{\mathrm{t}}$ are the initial and residual concentrations of NOM $(\mathrm{mg} / \mathrm{L})$, respectively.

Blank samples were used as control for each series of the experiments. The amount of adsorbed NOM on SMZ was calculated using the following equation:

$$
q_{e}=\left[\frac{C_{0}-C_{e}}{M}\right] \times V
$$

Where $\mathrm{C}_{0}$ and $\mathrm{C}_{\mathrm{e}}$ are the initial and equilibrium liquidphase concentrations of NOM, respectively $(\mathrm{mg} / \mathrm{L}), \mathrm{V}$ is the volume of the solution ( $\mathrm{L}$ ), and $\mathrm{M}$ is the weight of the used adsorbent (g) (30).

\section{Results}

\subsection{Characterization of Natural and Modified Zeolites}

The surface of the natural zeolite was observed using a SEM device (Figure 1).

The chemical compositions of the zeolite are given in Table 1. The cation exchange capacity (CEC) and external cation exchange capacity (ECEC) of the natural zeolite were determined to be $1.85 \mathrm{meq} / \mathrm{g}$ and $0.205 \mathrm{meq} / \mathrm{g}$, respectively.

\subsection{Effects of Different Types of Modified Zeolite}

The removal efficiencies of different types of modified zeolites are shown in Figure 2. Figure 2 shows the SMZ3 in comparison with natural zeolite, SMZ1 and SMZ2, which has higher capacity to absorb NOM.

\subsection{Effect of $p H$}

The effect of $\mathrm{pH}$ on the removal of HA by SMZ is shown in Figure 3. It should be noted that the increase in negative charge of HA with increasing $\mathrm{pH}$ did not bring about an increase in HA adsorption at higher pH levels.

\subsection{Effect of Adsorbent Dose}

Figure 4 presents the effect of adsorbent dose on NOM removal at different initial concentrations of $\operatorname{NOM}(5,10$, 20 and $50 \mathrm{mg} / \mathrm{L}$ ). The experiments showed that with increase in the amount of the adsorbent dose from 0.2 to 1.2 $\mathrm{g} / \mathrm{L}$, the efficiency of NOM removal increased for all NOM concentrations.

\subsection{Adsorption Isotherm}

In this study, experiment data was analyzed by the Langmuir and Freundlich isotherm models. The linear form of Langmuir equation is given as:

$$
\frac{C_{e}}{q_{e}}=\frac{1}{\left(q_{m} K_{1}\right)}+\left(\frac{1}{q_{m}}\right) C_{e}
$$

where $C_{e}(\mathrm{mg} / \mathrm{L})$ is the equilibrium concentration of NOM in solution, $\mathrm{q}_{\mathrm{e}}(\mathrm{mg} / \mathrm{g})$ is the amount of adsorbed NOM onto SNZ3 at equilibrium, $\mathrm{q}_{\mathrm{m}}(\mathrm{mg} / \mathrm{g})$ is the maximum adsorption capacity, and $\mathrm{Kl}(\mathrm{L} / \mathrm{mg})$ is the Langmuir constant related to energy sorption; the plot of $\mathrm{c}_{\mathrm{e}} / \mathrm{q}_{\mathrm{e}}$ against $c_{e}$ gives a straight line (Figure 5); the slope and intercept of this line correspond to $\mathrm{q}_{\mathrm{m}}$ and $\mathrm{K}_{\mathrm{l}}$, respectively (31). The calculated correlation coefficients $\left(\mathrm{r}^{2}\right)$ and the Langmuir constant for NOM are presented in Table 2. Investigation of this table shows that the maximum NOM sorption capacity of SMZ3 (qm) and the $\mathrm{r}^{2}$ value were found 111.23 $\mathrm{mg} / \mathrm{g}$ and 0.97 at $25^{\circ} \mathrm{C}$, respectively. The $\mathrm{r}^{2}$ of Langmuir isotherm was greater than that of the Freundlich isotherm for the adsorption of NOM. This implies that the adsorption of NOM onto SMZ3 was better depicted by the Langmuir model than the Freundlich model.

The essential attributes of dimensionless separation factor RL can be written as Equation below:below:

$$
R_{L}=\frac{1}{\left(1+C_{0} K_{1}\right)}
$$

Where $\mathrm{K}_{\mathrm{l}}(\mathrm{L} / \mathrm{mg})$ is the Langmuir constant and $\mathrm{C}_{0}(\mathrm{mg} / \mathrm{g})$ is the initial concentration of NOM. $R_{L}$ values between 0 and 1 indicate favorable adsorption. The adsorption process is irreversible when $R_{L}$ is 0 , linear when $R_{L}$ is 1 , and unfavorable when $R_{L}$ is greater than 1 . By calculating the $R_{L}$ values for examined adsorption system, values were found from 0.084 to 0.64 for NOM concentrations ranging from 5 to $100 \mathrm{mg} / \mathrm{L}$ at $25^{\circ} \mathrm{C}$ (Table 2). Accordingly, these values showed that the adsorption process was favorable. Freundlich is another isotherm model for adsorption on amorphous surfaces. It assumes the heterogeneity of surface and the exponential distribution of active sites 
and their energies (32). The linear form of Freundlich isotherm is presented as the following Equation:

$$
\log q_{e}=\log K_{f}+\frac{1}{n} \log C_{e}
$$

Where $\mathrm{C}_{\mathrm{e}}(\mathrm{mg} / \mathrm{L})$ is the equilibrium concentration of the adsorbate, $\mathrm{q}_{\mathrm{e}}(\mathrm{mg} / \mathrm{g})$ is the amount of NOM adsorbed per unit mass of adsorbent, $\mathrm{K}_{\mathrm{F}}(\mathrm{mg} / \mathrm{g})$ and $\mathrm{n}$ are Freundlich constants with $\mathrm{n}$ giving an indication of how favorable the adsorption process is and $\mathrm{K}_{\mathrm{F}}$ is the adsorption capacity of the adsorbent. These constants can be determined from the linear plot of $\log \mathrm{q}_{\mathrm{e}}$ versus $\log \mathrm{C}_{\mathrm{e}}$ (Figure 6). $\mathrm{K}_{\mathrm{F}}$ can be explained as the adsorption or distribution coefficient and represents the quantity of NOM adsorbed onto SMZ3 for a unit equilibrium concentration. The magnitude of the exponent, $1 / \mathrm{n}$, gives an indication of the favorability of adsorption. Values of $n>1$ represent favorable adsorption conditions (32). Values of $\mathrm{K}_{\mathrm{F}}$ and $\mathrm{n}$ are calculated from the intercept and slope of the plot, respectively, and are listed in Table 2. The results suggest that NOM was favorably adsorbed by ZMS3. However, the values of the correlation coefficient $\left(\mathrm{r}^{2}\right)$ indicated that the Langmuir isotherm NOMs were best fitted for the adsorption of NOM on SMZ3 all abbreviation are presented in Table 3.

Figure 1. Scanning Electron Microscopy Images of the Natural Zeolite Before and After the Modification

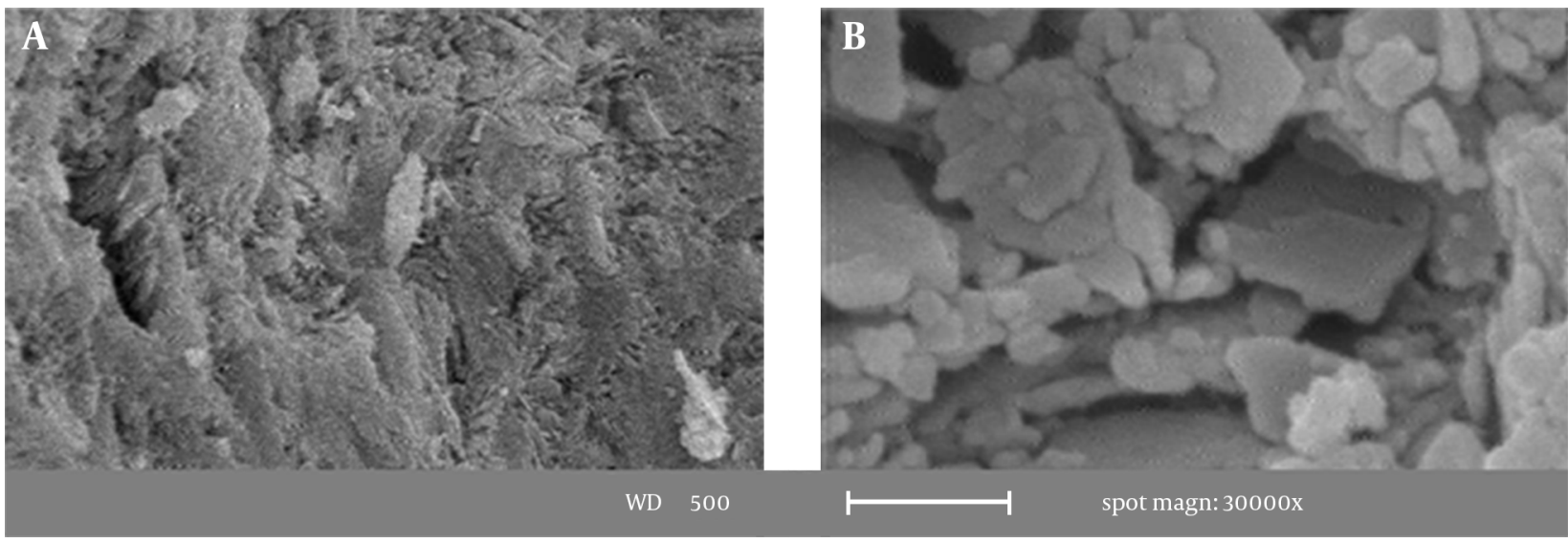

Left slide, before the modification; right slide, after the modification.

\begin{tabular}{|c|c|}
\hline Component & $\mathbf{w} / \mathbf{w}, \%$ \\
\hline $\mathrm{SiO}_{2}$ & 69.321 \\
\hline $\mathrm{Al}_{3} \mathrm{O}_{2}$ & 10.475 \\
\hline $\mathrm{Na}_{2} \mathrm{O}$ & 2.224 \\
\hline MgO & 0.41 \\
\hline $\mathrm{P}_{50} \mathrm{O}_{2}$ & 0.02 \\
\hline $\mathrm{SO}_{3}$ & 0.045 \\
\hline $\mathbf{K}_{2} \mathbf{O}$ & 4.028 \\
\hline $\mathrm{CaO}$ & 1.289 \\
\hline $\mathrm{TiO}_{2}$ & 0.191 \\
\hline $\mathrm{Fe}_{2} \mathrm{O}_{3}$ & 0.662 \\
\hline $\mathrm{Sr}$ & 0.028 \\
\hline $\mathbf{Z r}$ & 11.27 \\
\hline Loss by ignition & 0.017 \\
\hline
\end{tabular}


Figure 2. Effect of Different Types of Surfactant-Modified Zeolite on Natural Organic Matter Removal Efficiency

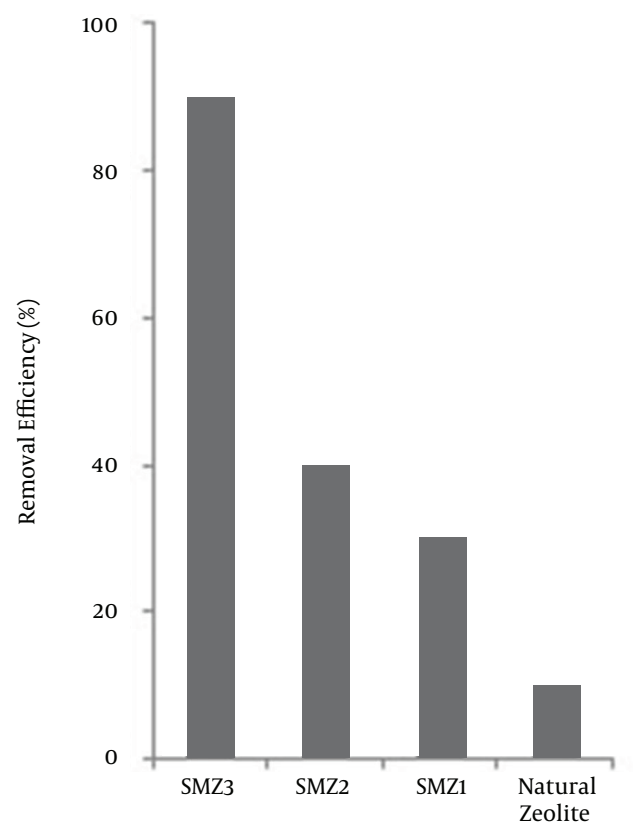

Different Types of Zeolite

Initial concentration $=10 \mathrm{mg} / \mathrm{L}, \mathrm{pH}=7$, adsorbent dose $=0.8 \mathrm{~g} / \mathrm{L}$.

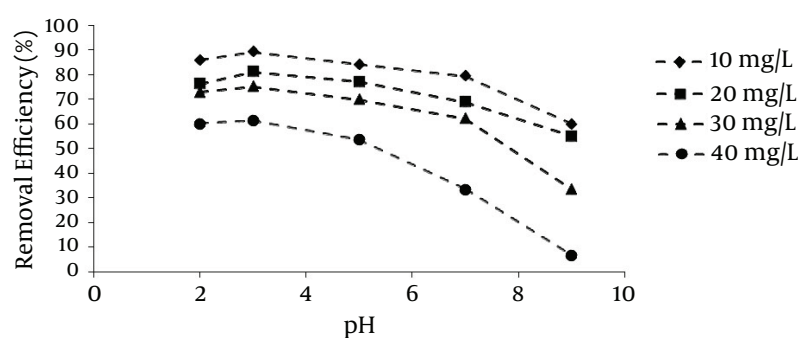

Figure 3. Effect of pH on the Removal of Humic Acid by Surfactant-Modified Zeolite
Figure 4. Effect of Adsorbent Dose on Natural Organic Matter Removal Efficiency and qe

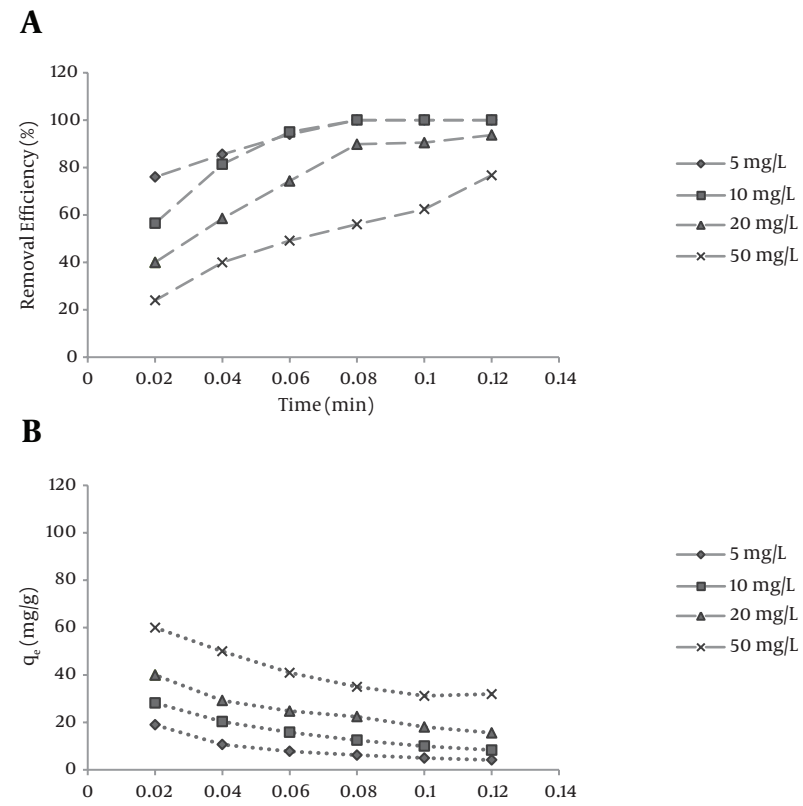

qe, the amount of adsorbed NOM onto SNZ3 at equilibrium; $\mathrm{pH}=5$ and $\mathrm{t}$ $=300$ minutes.

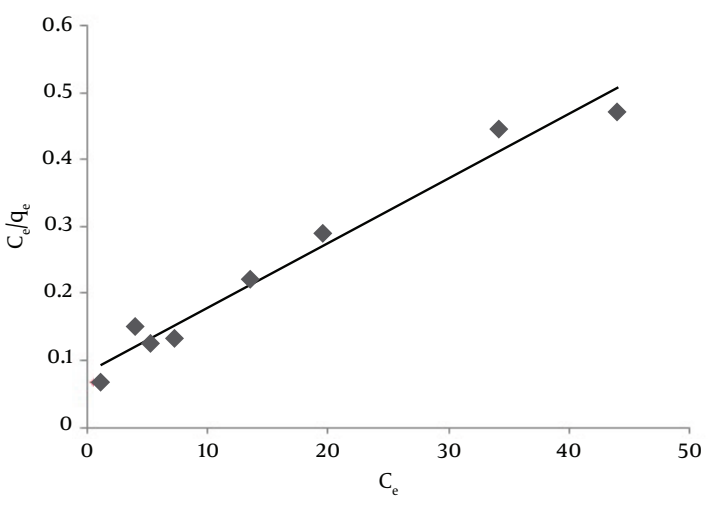

Figure 5. Langmuir Adsorption Isotherm of Natural Organic Matter onto Surfactant-Modified Zeolite 3

Table 2. Isotherm Parameters and Correlation Coefficients for Natural Organic Matter Adsorption Onto Surfactant-Modified Zeolite 3

\begin{tabular}{|c|c|c|c|c|c|c|c|}
\hline \multirow[t]{2}{*}{$\mathbf{T},{ }^{\circ} \mathbf{C}$} & \multicolumn{4}{|c|}{ Langmuir } & \multicolumn{3}{|c|}{ Freundlich } \\
\hline & $\mathbf{q}_{\mathrm{m}}, \mathbf{m g} / \mathrm{g}$ & $\mathbf{K}_{\mathrm{l}}, \mathbf{L} / \mathbf{m g}$ & $\mathbf{r}^{2}$ & $\mathbf{R}_{\mathrm{L}}$ & $\mathbf{n}$ & $\mathbf{k}_{\mathrm{f}}, \mathbf{m g} / \mathbf{g}$ & $\mathbf{r}^{2}$ \\
\hline 25 & 111.23 & 0.1084 & .97 & $0.084 \sim 0.64$ & 2.12 & 16.5 & .893 \\
\hline
\end{tabular}


Mahvi AH et al.

\begin{tabular}{|c|c|c|}
\hline & Dfi & Unit \\
\hline $\mathrm{C}_{\mathbf{0}}$ & Initial concentrations of humic acid & $\mathrm{mg} / \mathrm{L}$ \\
\hline $\mathbf{C}_{\mathbf{e}}$ & Equilibrium concentrations of humic acid & $\mathrm{mg} / \mathrm{L}$ \\
\hline qe & Amount of adsorbed humic acid at equilibrium & $\mathrm{mg} / \mathrm{g}$ \\
\hline M & Weight of the adsorbent used & g \\
\hline $\mathbf{V}$ & Volume & $\mathrm{L}$ \\
\hline $\mathrm{C}_{\mathrm{t}}$ & Concentrations of humic acid at time & $\mathrm{mg} / \mathrm{L}$ \\
\hline$q_{t}$ & Amount of adsorbed humic acid at time & $\mathrm{mg} / \mathrm{g}$ \\
\hline$K_{1}$ & Constant rate of adsorption & $\min -1$ \\
\hline $\mathbf{K}_{\mathbf{2}}$ & Equilibrium rate constant & gmg-1min-1 \\
\hline $\mathbf{r}^{2}$ & Correlation coefficients & Dimensionless \\
\hline $\mathbf{t}$ & Time & s \\
\hline $\mathbf{R}_{\mathbf{L}}$ & Separation factor & Dimensionless \\
\hline $\mathbf{K}_{\mathbf{l}}$ & Langmuir constant & $\mathrm{L} / \mathrm{mg}$ \\
\hline $\mathbf{K}_{\mathbf{F}}$ & Freundlich constant & $(\mathrm{mg} / \mathrm{g})$ \\
\hline $\mathbf{n}$ & Adsorption process indicator & Dimensionless \\
\hline
\end{tabular}

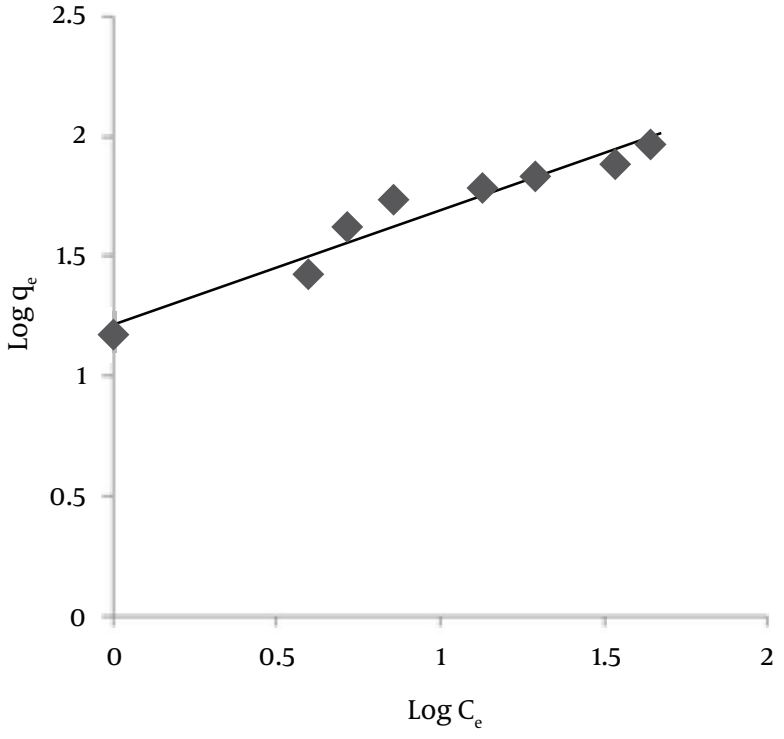

Figure 6. Freundlich Adsorption Isotherm of Natural Organic Matter Onto Surfactant-Modified Zeolite 3

\section{Discussion}

During the recent decades, NOM has been found in many surface water sources. NOM is one of the main components of organic matter which form the major portion of dissolved organic materials. According to the results of this study, SMZ3 as the zeolite loaded with a surfactant concentration greater than CMC had a higher capacity to adsorb NOM; therefore, among the other types of adsorbents, SMZ3 was chosen as the best adsorbent and used for the next experiments. Based on the result of this study, NOM ex- hibited high adsorption at low pH and decreasing adsorption as $\mathrm{pH}$ increased. Other studies have presented similar results. Li et al. determined adsorbent levels in SMZ for the removal of HA from water and reported an increasing adsorption relationship with low $\mathrm{pH}$ (8). Based on the result of a study by Abate, $\mathrm{pH}$ and ionic strength were related to removal processes of a sedimentary HA in a suspension of vermiculite. They showed that low $\mathrm{pH}$ had an influence on adsorbent levels (33). In another case, Yan and Bai found an association of adsorption of lead and HA with chitosan hydrogel beads (34). The results indicated that similar behavior was observed for HA by chitosan adsorbents (34). According to the results obtained through other surveys and the present study, the investigation of the adsorption of bisphenol A by SMZ recommended that anionic species had greater affinity toward SMZ than neutral species due to the enhanced interaction between negatively charged bisphenol A anions and the positively charged head of hexadecyltrimethylammonium (HDTMA) (35). However, unlike bisphenol A, HA is a macromolecule that can possess a negative charge, even at $\mathrm{pH}$ levels as low as $\mathrm{pH}$, due to the deprotonation of carboxylic groups, although a $\mathrm{pH}$ above around neutral is required to enable phenol groups to dissociate (35). Hence, HA behaves as a polyanion in water, unless the $\mathrm{pH}$ is extremely acidic. However, the negative charge of HA still increases with increasing $\mathrm{pH}$, because the deprotonation of HA increases continuously with $\mathrm{pH}$ in the $\mathrm{pH}$ range analyzed. Although, a negatively charged organic molecule would have higher affinity to interact with the positively charged head of surfactant, similarly to bisphenol A. According to our results, the increase in negative charge of HA with increasing $\mathrm{pH}$ did not bring about an increase in HA adsorption at higher pH levels (Figure 3), suggesting that the influence of $\mathrm{pH}$ on HA adsorption by SMZ could barely be interpreted by ionization of the molecule. 
$\mathrm{pH}$ value is one of the most important parameters affecting adsorption behavior, because it also controls the adsorbent surface charge. Figure 4 illustrates the quantities of adsorbed NOM (mg/g) for different NOM concentrations decreased with increase in the adsorbent dose. According to Figure 4, the amount of qe (mg/g) for initial concentration of $5 \mathrm{mg} / \mathrm{L}$ decreased from 19 to $4.1 \mathrm{mg} / \mathrm{g}$, and for initial concentration of $50 \mathrm{mg} / \mathrm{L}$ it decreased from 60 to $32 \mathrm{mg} / \mathrm{g}$ with an increasing adsorbent dose from 0.2 to $1.2 \mathrm{~g} / \mathrm{L}$. Zhan et al. assessed the removal of HA from aqueous solution by cetylpyridinium bromide modified zeolite. Based on their results, adsorbed NOM concentrations decreased with increase in the adsorbent dose (23). In a similar work in 2010, Torabian et al. estimated the effect of surfactant-modified natural zeolite on removal of petroleum aromatic hydrocarbons (26). The result of this study is similar to our study (26). It is easily understood that the number of available adsorption sites increases by increasing the adsorbent dose, which results in the increased percentage of NOM removal. On the other hand, the experiments showed that the adsorption amount per mass unit $\left(\mathrm{q}_{\mathrm{t}}\right)$ decreased with increasing the adsorbent dose, which was due to unsaturated sites of adsorbent through the adsorption process $(23,36)$. Based on the results of this study, the NOM adsorption capacity of $\operatorname{SMZ3}\left(\mathrm{q}_{\mathrm{m}}\right)$ was $111.23 \mathrm{mg} / \mathrm{g}$, which is comparable with other adsorbents such as activated carbon from rice husk (45.4 $\mathrm{mg} / \mathrm{g}$ ) (37), crosslinked chitosan-epichlorohydrin beads (44.84 mg/g) (18), fly ash (10.7 mg/g) (17), aminopropyl functionalized SBA-15 (117.6 mg/g) (38), polypyrrole-coated glass beads (0.396 mg/g) (39), and aminated polyacrylonitrile fibers $(16.22 \mathrm{mg} / \mathrm{g})(40)$.

\subsection{Conclusions}

The results showed that SMZ can be used as low-cost adsorbent for the adsorption of NOM from aqueous solutions. The adsorption of NOM by SMZ enhanced at acidic $\mathrm{pH}$ levels. Results from this study indicated that SDSmodified natural zeolite with a surfactant bilayer coverage was a favorable adsorbent for the removal of NOM from aqueous solutions. The equilibrium data fitted well with Langmuir isotherm. The maximum adsorption capacity of SMZ with surfactant bilayer coverage for NOM was $111 \mathrm{mg} / \mathrm{g}$ at $25^{\circ} \mathrm{C}$ and $\mathrm{pH}=5$.

\section{Acknowledgments}

The authors would like to appreciate the financial support of the deputy of research, Tehran university of medical sciences.

\section{Footnotes}

Authors' Contribution:Amir Hosein Mahvi, Mehdi Vosoughi, , Mohammad Javad Mohammadi, Bayram Hashemzadeh, Anvar Asadi, Amir Zahedi, Soudabeh Pourfadakar.

Funding/Support:This study was financially supported by Ahvaz Jundishapur university of medical sciences.

\section{References}

1. Wang S, Gong W, Liu X, Gao B, Yue Q. Removal of fulvic acids using the surfactant modified zeolite in a fixed-bed reactor. Separat PurifTechnol. 2006;51(3):367-73.

2. Brigante M, Zanini G, Avena M. On the dissolution kinetics of humic acid particles. Effect of monocarboxylic acids. Chemosphere. 2008;71(11):2076-81. doi: 10.1016/j.chemosphere.2008.01.038. [PubMed: 18328533]

3. Zazouli MA, Nasseri S, Mahvi AH, Mesdaghinia AR, Younecian M, Gholami M. Determination of hydrophobic and hydrophilic fractions of natural organic matter in raw water of Jalalieh and Tehranspars water treatment plants (Tehran). J Appl Sci. 2007;7(18):2651-5.

4. Brigante M, Zanini G, Avena M. Effect of $\mathrm{pH}$, anions and cations on the dissolution kinetics of humic acid particles. Colloids Surfaces Physicochem Engin Aspects. 2009;347(1):180-6.

5. Zazouli MA, Nasseri S, Mahvi AH, Gholami M, Mesdaghinia AR, Younesian M. Retention of humic acid from water by nanofiltration membrane and influence of solution chemistry on membrane performance. Iran J Environ Health Sci Engin. 2008;5(1):11-8.

6. Sadat Taghavirad S, Takdastan A, Mohammadi MJ, Montazeri Zadeh S. Evaluation of wastewater treatment plant Specialty and subspecialty Hospital Mehr Ahvaz, Iran. J Torbat Heydariyeh Univ Med Sci. 2015;2(1):47-54.

7. Bazrafshan E, Biglari H, Mahvi AH. Humic acid removal from aqueous environments by electrocoagulation process using iron electrodes. J Chem. 2012;9(4):2453-61.

8. Li C, Dong Y, Wu D, Peng L, Kong H. Surfactant modified zeolite as adsorbent for removal of humic acid from water. Appl Clay Sci. 2011:52(4):353-7.

9. Ahmadi M, Mohammadi MJ, Ahmadi-Angaly K, Babaei AA. Failures analysis of water distribution network during 2006-2008 in Ahvaz, Iran. J Adv Environ Health Res. 2014;1(2):129-37.

10. Anirudhan TS, Ramachandran M. Surfactant-modified bentonite as adsorbent for the removal of humic acid from wastewaters. Appl Clay Sci. 2007;35(3):276-81.

11. Imyim A, Prapalimrungsi E. Humic acids removal from water by aminopropyl functionalized rice huskash.JHazard Mater.2010;184(13):775-81. doi:10.1016/j.jhazmat.2010.08.108. [PubMed: 20869173]

12. Nadafi K, Vosoughi M, Asadi A, Borna M, Shirmardi M. Reactive Red 120 dye removal from aqueous solution by adsorption on nano-alumina. J Water Chem Technol. 2014;36(3):125-33.

13. Chiang PC, Chang EE, Chang PC, Huang CP. Effects of preozonation on the removal of THM precursors by coagulation. Sci Total Environ. 2009;407(21):5735-42. doi: 10.1016/j.scitotenv.2009.07.024. [PubMed:19674771]

14. Christl I, Kretzschmar R. C-1s NEXAFS spectroscopy reveals chemical fractionation of humic acid by cation-induced coagulation. Environ Sci Technol. 2007;41(6):1915-20. [PubMed: 17410784]

15. Landrum PF, Nihart SR, Eadie BJ, Gardner WS. Reverse-phase separation method for determining pollutant binding to Aldrich humic acid and dissolved organic carbon of natural waters. Environ Sci Technol.1984;18(3):187-92. doi:10.1021/es00121a010. [PubMed: 22263733]

16. Chen JP, Wu S. Simultaneous adsorption of copper ions and humic acid onto an activated carbon.JColloid Interface Sci.2004;280(2):33442. doi: 10.1016/j.jcis.2004.08.029. [PubMed: 15533405]

17. Wang S, Zhu ZH. Humic acid adsorption on fly ash and its derived unburned carbon. J Colloid Interface Sci. 2007;315(1):41-6. doi: 10.1016/j.jcis.2007.06.034. [PubMed:17628583]

18. Wan Ngah WS, Hanafiah MA, Yong SS. Adsorption of humic acid from aqueous solutions on crosslinked chitosan-epichlorohydrin beads: kinetics and isotherm studies. Colloids Surf B Biointerfaces. 2008;65(1):18-24. doi: 10.1016/j.colsurfb.2008.02.007. [PubMed:18359205]

19. Ravichandran M, Aiken GR, Reddy MM, Ryan JN. Enhanced Dissolution of Cinnabar (Mercuric Sulfide) by Dissolved Organic Matter Isolated from the Florida Everglades. Environ Sci Technol. 1998;32(21):3305-11. doi: 10.1021/es9804058.

20. Zhou Q, Maurice PA, Cabaniss SE. Size fractionation upon adsorption of fulvic acid on goethite: equilibrium and kinetic studies. Geochimica et Cosmochimica Acta. 2001;65(5):803-12. doi: 10.1016/ s0016-7037(00)00536-6. 
21. Ding C, Shang C. Mechanisms controlling adsorption of natural organic matter on surfactant-modified iron oxide-coated sand. Water Res. 2010;44(12):3651-8. doi: 10.1016/j.watres.2010.04.014. [PubMed: 20457463]

22. Lin J, Zhan Y, Zhu Z, Xing Y. Adsorption of tannic acid from aqueous solution onto surfactant-modified zeolite. J Hazard Mater 2011;193:102-11. doi: 10.1016/j.jhazmat.2011.07.035. [PubMed: 21813239]

23. Zhan Y, Zhu Z, Lin J, Qiu Y, Zhao J. Removal of humic acid from aqueous solution by cetylpyridinium bromide modified zeolite. J Environ Sci (China). 2010;22(9):1327-34. [PubMed: 21174962]

24. Niri MV, Mahvi AH, Alimohammadi M, Shirmardi M, Golastanifar $\mathrm{H}$, Mohammadi MJ, et al. Removal of natural organic matter (NOM) from an aqueous solution by $\mathrm{NaCl}$ and surfactant-modified clinoptilolite. J Water Health. 2015;13(2):394-405. doi:10.2166 wh.2014.088. [PubMed:26042972]

25. Koh SM, Dixon JB. Preparation and application of organo-minerals as sorbents of phenol, benzene and toluene. Appl Clay Sci. 2001;18(3-4):111-22. doi: 10.1016/s0169-1317(00)00040-5.

26. Torabian A, Kazemian H, Seifi L, Bidhendi G, Azimi AA, Ghadiri SK Removal of Petroleum Aromatic Hydrocarbons by Surfactantmodified Natural Zeolite: The Effect of Surfactant. Clean Soil Air Water. 2010;38(1):77-83. doi:10.1002/clen.200900157.

27. Ghiaci M, Abbaspur A, Kia R, Seyedeyn-Azad F. Equilibrium isotherm studies for the sorption of benzene, toluene, and phenol onto organo-zeolites and as-synthesized MCM-41. Separat Purif Technol. 2004;40(3):217-29. doi:10.1016/j.seppur.2004.03.001.

28. Haggerty GM, Bowman RS. Sorption of chromate and other inorganic anions by organo-zeolite. Environ Sci Technol. 1994;28(3):452-8. doi: 10.1021/es00052a 017. [PubMed: 22165880]

29. Wang S, Li H, Xie S, Liu S, Xu L. Physical and chemical regeneration of zeolitic adsorbents for dye removal in wastewater treatment. Chemosphere. 2006;65(1):82-7. doi: 10.1016/j.chemosphere.2006.02.043. [PubMed:16581100]

30. Shirmardi M, Mahvi AH, Hashemzadeh B, Naeimabadi A, Hassan G, Niri MV. The adsorption of malachite green (MG) as a cationic dye onto functionalized multi walled carbon nanotubes. Korean
JChem Engin. 2013:30(8):1603-8. doi:10.1007/s11814-013-0080-1.

31. Tunali S, Ozcan AS, Ozcan A, Gedikbey T. Kinetics and equilibrium studies for the adsorption of Acid Red 57 from aqueous solutions onto calcined-alunite. J Hazard Mater. 2006;135(1-3):141-8. doi: 10.1016/j.jhazmat.2005.11.033. [PubMed:16386839]

32. Fytianos K, Voudrias E, Kokkalis E. Sorption-desorption behaviour of 2,4-dichlorophenol by marine sediments. Chemosphere. 2000;40(1):3-6. [PubMed:10665437]

33. Abate $\mathrm{G}$, Masini JC. Influence of $\mathrm{pH}$ and ionic strength on removal processes of a sedimentary humic acid in a suspension of vermiculite. Colloids Surfaces Physicochem Engin Aspects. 2003;226(13):25-34. doi: 10.1016/s0927-7757(03)00418-7.

34. Yan WL, Bai R. Adsorption of lead and humic acid on chitosan hydrogel beads. Water Res. 2005;39(4):688-98. doi: 10.1016/j.watres.2004.11.007. [PubMed:15707642]

35. Dong Y, Wu D, Chen X, Lin Y. Adsorption of bisphenol A from water by surfactant-modified zeolite. J Colloid Interface Sci. 2010;348(2):585-90. doi: 10.1016/j.jcis.2010.04.074. [PubMed 20621825]

36. Monash P, Pugazhenthi G. Investigation of equilibrium and kinetic parameters of methylene blue adsorption onto MCM-41 Korean J Chem Engin. 2010;27(4):1184-91. doi: 10.1007/s11814-0100177-8

37. Daifullah AAM, Girgis BS, Gad HMH. A study of the factors affecting the removal of humic acid by activated carbon prepared from biomass material. Colloids Surfaces Physicochem Engin Aspects. 2004;235(1-3):1-10. doi:10.1016/j.colsurfa.2003.12.020.

38. Tao $\mathrm{Q}, \mathrm{Xu} \mathrm{Z}$, Wang J, Liu F, Wan $\mathrm{H}$, Zheng S. Adsorption of humic acid to aminopropyl functionalized SBA-15. Microporous Mesoporous Materials. 2010;131(1-3):177-85. doi:10.1016/j.micromeso.2009.12.018.

39. Bai R, Zhang X. Polypyrrole-Coated Granules for Humic Acid Removal. J Colloid Interface Sci. 2001;243(1):52-60. doi: 10.1006 jcis.2001.7843.

40. Deng S, Bai R. Adsorption and desorption of humic acid on aminated polyacrylonitrile fibers. J Colloid Interface Sci. 2004;280(1):36-43.[PubMed: 15476771] 